\title{
Active Dendritic Properties and Local Inhibitory Input Enable Selectivity for Object Motion in Mouse Superior Colliculus Neurons
}

\author{
Samuel D. Gale and ${ }^{-G}$ Gabe J. Murphy \\ Janelia Research Campus, Howard Hughes Medical Institute, Ashburn, Virginia 20147
}

Neurons respond to specific features of sensory stimuli. In the visual system, for example, some neurons respond to motion of small but not large objects, whereas other neurons prefer motion of the entire visual field. Separate neurons respond equally to local and global motion but selectively to additional features of visual stimuli. How and where does response selectivity emerge? Here, we show that wide-field (WF) cells in retino-recipient layers of the mouse superior colliculus (SC) respond selectively to small moving objects. Moreover, we identify two mechanisms that contribute to this selectivity. First, we show that input restricted to a small portion of the broad dendritic arbor of WF cells is sufficient to trigger dendritic spikes that reliably propagate to the soma/axon. In vivo whole-cell recordings reveal that nearly every action potential evoked by visual stimuli has characteristics of spikes initiated in dendrites. Second, inhibitory input from a different class of SC neuron, horizontal cells, constrains the range of stimuli to which WF cells respond. Horizontal cells respond preferentially to the sudden appearance or rapid movement of large stimuli. Optogenetic reduction of their activity reduces movement selectivity and broadens size tuning in WF cells by increasing the relative strength of responses to stimuli that appear suddenly or cover a large region of space. Therefore, strongly propagating dendritic spikes enable small stimuli to drive spike output in WF cells and local inhibition helps restrict responses to stimuli that are both small and moving.

Key words: dendrite; motion; superior colliculus; vision

Significance Statement

How do neurons respond selectively to some sensory stimuli but not others? In the visual system, a particularly relevant stimulus feature is object motion, which often reveals other animals. Here, we show how specific cells in the superior colliculus, one synapse downstream of the retina, respond selectively to object motion. These wide-field (WF) cells respond strongly to small objects that move slowly anywhere through a large region of space, but not to stationary objects or full-field motion. Action potential initiation in dendrites enables small stimuli to trigger visual responses and inhibitory input from cells that prefer large, suddenly appearing, or quickly moving stimuli restricts responses of WF cells to objects that are small and moving.

\section{Introduction}

Visual motion is an important sensory cue (Frost, 2010). Global motion of the entire visual field, along with vestibular signals and motor-related corollary discharge, provides information about self-movement and helps animals monitor and stabilize their tra-

\footnotetext{
Received Feb. 26, 2016; revised July 5, 2016; accepted July 7, 2016.

Author contributions: S.D.G. and G.J.M. designed research; S.D.G. performed research; S.D.G. analyzed data; S.D.G. and G.J.M. wrote the paper.

This work was supported by the Howard Hughes Medical Institute. We thank Reza Behnam for sharing virus; Sarah Lindo for stereotaxic injections; John Macklin and Katie Bittner for help with optical fibers; Susan Michael for assisting with histology; and Abby Person, Corbett Bennett, Sonja Hofer, and Spencer Smith for helpful comments. The authors declare no competing financial interests.

S. D. Gale's and G. J. Murphys' present affiliation: Allen Institute for Brain Science, Seattle, WA.

Correspondence should be addressed to Samuel D. Gale, Allen Institute for Brain Science, 615 Westlake Avenue, Seattle, WA 98109. E-mail: samg@alleninstitute.org.

DOI:10.1523/JNEUROSCI.0645-16.2016

Copyright $\odot 2016$ the authors $\quad 0270-6474 / 16 / 369111-13 \$ 15.00 / 0$
}

jectory through space. Local (object) motion facilitates detection and tracking of other animals and often triggers shifts in spatial attention and associated orienting movements.

Where and how does the visual system encode object motion? One possibility is that object motion is detected as early the retina, where a subset of retinal ganglion cells (RGCs) respond to differential motion of their receptive field center and surround (Olveczky et al., 2003; Zhang et al., 2012). However, these cells, like RGCs that respond to motion onset or reversal (Schwartz et al., 2007; Chen et al., 2013) or RGCs that are tuned to movement speed and direction (Oyster, 1968), also respond to the sudden appearance/disappearance of stationary stimuli and therefore do not specifically signal object motion.

One synapse downstream of the retina, wide-field (WF) cells in the superficial superior colliculus (sSC) are potentially well suited to selectively encode information about object motion rather than sud- 
den changes in the environment or global motion. WF cells respond weakly (if at all) to large, suddenly appearing stimuli or full-field drifting gratings. Conversely, they respond comparatively strongly to small, slowly moving stimuli presented anywhere within a large region of space (Gale and Murphy, 2014).

A variety of mechanisms might contribute to response selectivity in WF cells. First, some response properties of WF cells could reflect properties of the input that they receive from retina or cortex (Gabriel et al., 2012; Hunter et al., 2013; Preuss et al., 2014). Second, active dendrites or other intrinsic properties could enhance selectivity of spike output relative to weakly selective input (Smith et al., 2013). Third, untuned inhibition could enhance selectivity by narrowing the range of tuned excitatory input that crosses the spike threshold (Isaacson and Scanziani, 2011). Finally, tuned inhibition or other mechanisms could generate selectivity de novo. For example, in the zebrafish optic tectum and mouse visual cortex, inhibitory interneurons that pool excitatory input over a wide region prefer large stimuli and contribute to opposing selectivity for small stimuli in cells that they target (Del Bene et al., 2010; Adesnik et al., 2012).

Here, we identify mechanisms underlying response selectivity in WF cells. First, by comparing responses to a variety of visual stimuli, we show that translational motion of small objects most strongly drives spike output in WF cells; full-field motion is an ineffective stimulus on its own and strongly suppresses responses to object motion. We then demonstrate that individual dendrites of WF cells can independently initiate strongly propagating dendritic spikes, and that nearly all spike output in response to visual stimuli is driven by such spikes. Last, we show that response selectivity in WF cells is at least partly explained by the inhibitory input that they receive from horizontal cells, the predominant (if not exclusive) class of GABAergic neurons in the sSC. These horizontal cells respond preferentially to many characteristics of visual stimuli to which WF cells respond poorly and hyperpolarizing them broadens size tuning and reduces movement selectivity in WF cells.

\section{Materials and Methods}

Mice. All procedures were approved by the Janelia Research Campus Institutional Animal Care and Use Committee. CB57BL/6J mice of either sex were 6-18 weeks old at the time of all in vitro and in vivo electrophysiological recordings. For some experiments, we used the following transgenic mice: Ntsr1-GN209-Cre (Gerfen et al., 2013) crossed to Ai32 (Madisen et al., 2012), vGAT-ChR2 (Zhao et al., 2011), or Gad2-Cre (Taniguchi et al., 2011).

In vitro electrophysiology, imaging, uncaging, and optogenetics. Fourhundred-micrometer-thick parasagittal brain slices were cut with a vibratome (Leica) in chilled cutting solution containing the following (in mM): 60 sucrose, $83 \mathrm{NaCl}, 25 \mathrm{NaHCO}_{3}, 1.25 \mathrm{NaH}_{2} \mathrm{PO}_{4}, 2.5 \mathrm{KCl}, 0.5$ $\mathrm{CaCl}_{2}, 6 \mathrm{MgCl}_{2}, 20 \mathrm{D}$-glucose, $3 \mathrm{Na}$ pyruvate, and 1 ascorbic acid. Slices were transferred to warm $\left(34^{\circ} \mathrm{C}\right)$ cutting solution, which was then allowed to cool to room temperature. Approximately $60 \mathrm{~min}$ after cutting, slices were transferred to artificial CSF (ACSF) containing the following (in mM): $125 \mathrm{NaCl}, 25 \mathrm{NaHCO}_{3}, 1.25 \mathrm{NaH}_{2} \mathrm{PO}_{4}, 2.5 \mathrm{KCl}, 1.3 \mathrm{CaCl}_{2}, 1$ $\mathrm{MgCl}_{2}, 20 \mathrm{D}$-glucose, $3 \mathrm{Na}$ pyruvate, and 1 ascorbic acid for recording (at $32^{\circ} \mathrm{C}$ ) or further storage (at room temperature).

Whole-cell current-clamp recordings were made with glass pipettes filled with the following (in mM): $134 \mathrm{~K}$ gluconate, $6 \mathrm{KCl}, 4 \mathrm{NaCl}, 10$ HEPES, 2 MgATP, 0.4 NaGTP, 10 tris phosphocreatine, 0.05 Na Alexa Fluor 594 hydrazide, and in some experiments 2 QX-314. Electrode resistance was 3-8 $\mathrm{M} \Omega$. Membrane voltage was amplified $50 \times$, low-pass filtered ( $4 \mathrm{kHz}$ cutoff) with a Multiclamp 700B amplifier (Molecular Devices), and digitized at 50 $\mathrm{kHz}$ with an ITC-18 data acquisition interface (Heka).

For $\mathrm{Ca}^{2+}$ imaging experiments, $0.1 \mathrm{~mm}$ Oregon green BAPTA-1 (OGB1) was included in the pipette internal solution. An arbitrarily shaped line crossing one or more dendritic segments was scanned with
$920 \mathrm{~nm}$ laser light via high-speed galvometers (Prairie Ultima). The linescan period was $1.1-4.3 \mathrm{~ms}$.

During two-photon glutamate uncaging experiments, $8.33 \mathrm{~mm}$ MNIglutamate in ACSF was pressure ejected from a glass pipette positioned at the surface of the slice above the uncaging location. Laser pulses $(720 \mathrm{~nm})$ of $0.2 \mathrm{~ms}$ duration were delivered at each of 13-25 sites on the distal dendrite of a WF cell with $0.2 \mathrm{~ms}$ between each pulse/site. No response was observed to laser pulses in the absence of MNI-glutamate.

To express channelrhodopsin-2 (ChR2) in RGCs, we injected $1 \mu \mathrm{l}$ of AAV-2.1-syn-ChR2-GFP into each eye and brain slices were prepared $4-5$ weeks later. ChR2 was activated with $1 \mathrm{~ms}$ LED flashes $(470 \mathrm{~nm}$ peak emission) delivered through a $63 \times$ objective. Synaptic responses were abolished after bath application of the $\mathrm{Na}^{+}$channel blocker TTX $(0.5$ $\mu \mathrm{M})$ or a combination of the AMPA and NMDA receptor antagonists $\operatorname{NBQX}(10 \mu \mathrm{M})$ and AP5 (50 $\mu \mathrm{M})$, respectively.

To express ChR2 or ArchT in horizontal cells, we injected $20 \mathrm{~nL}$ of AAV-2.1-syn-ChR2-2a-GFP or AAV-2.1-syn-ArchT-GFP into each of two sites bilaterally in the SC of Gad-Cre mice. Coordinates (in millimeters: anterior from lambda, lateral from midline, and depth) were 0.3 , $0.3,1.0$ and $0.1,0.8,1.0$. Recordings were performed $4-5$ weeks after virus injection.

In vivo electrophysiology, juxtacellular labeling, and optogenetics. Mice were anesthetized via intraperitoneal injection of urethane $(1.5 \mathrm{~g} / \mathrm{kg})$. Body temperature was maintained with a warm blanket under the animal. A craniotomy was made over the right SC and a plastic head holder was attached to the skull. For extracellular recordings, a glass electrode filled with $0.9 \% \mathrm{NaCl}$ and $1-1.5 \%$ neurobiotin was lowered into the right SC. Current pulses were used to monitor changes in pipette resistance. When a cell was encountered, pipette pressure (20-30 mbar) was released and a loose seal $(<20 \mathrm{M} \Omega)$ formed. Extracellular voltage signals were filtered $(0.1-4 \mathrm{kHz})$ and sampled at $20 \mathrm{kHz}$. Whole-cell recordings were obtained in vivo using the same internal solution described for in vitro experiments. Series resistance was $30-100 \mathrm{M} \Omega$ and action potentials always overshot $0 \mathrm{mV}$. For some recordings, an acid-etched optical fiber ( $9 \mu \mathrm{m}$ core) was positioned in the recording pipette $\sim 200-300 \mu \mathrm{m}$ from the tip, which enabled us to deliver light that activated ChR2 or ArchT.

Visual stimuli were back-projected on a screen at 120 frames/s with a modified digital light-processing projector and a SugarCube LED illuminator (Edmund Optics). The screen was $12.1 \mathrm{~cm}$ from the mouse's left eye and subtended $15-100^{\circ}$ laterally from directly in front of the mouse and $10^{\circ}$ below and $40^{\circ}$ above the mouse's eye. Spatial receptive fields were mapped by presenting upward and downward moving circular spots at varying azimuth and leftward and rightward moving spots at varying elevation; subsequently, stationary stimuli were presented at the subjectively chosen center of the spatial receptive field and moving stimuli crossed this location (Gale and Murphy, 2014). Background luminance was constant for the duration of each experiment. For one set of experiments, background was $0.2 \mathrm{~cd} / \mathrm{m}^{2}$ and spot stimuli were $48 \mathrm{~cd} / \mathrm{m}^{2}$; extracellular recordings with these particular light levels include WF and horizontal from our previous study (Gale and Murphy, 2014). In separate experiments, background luminance was $24 \mathrm{~cd} / \mathrm{m}^{2}$ and spots were $0.2 \mathrm{~cd} / \mathrm{m}^{2} ; 16$ and/or $48 \mathrm{~cd} / \mathrm{m}^{2}$ spots were also presented in a subset of these experiments. For random checkerboard stimuli, dark and light squares were 0.2 and $48 \mathrm{~cd} / \mathrm{m}^{2}$, respectively, and the luminance between trials was $24 \mathrm{~cd} / \mathrm{m}^{2}$. The random checkerboard was stationary for $0.5 \mathrm{~s}$ before and after stimulus movement. The size (pixels) and speed (pixels/ second) of circular spots and checkerboard squares were adjusted as a function of their position to maintain constant angular size and speed.

To express ArchT in horizontal cells, we injected $10 \mathrm{~nL}$ of AAV-2.1ArchT-GFP into each of two sites in the right SC of Gad-Cre mice (same coordinates as in vitro experiments). Recordings were performed 4-5 weeks after virus injection. An optical fiber was positioned inside the recording electrode $\sim 300 \mu \mathrm{m}$ from the tip. The $594 \mathrm{~nm}$ laser power was 2-5 $\mathrm{mW}$ at the tip of the optical fiber.

For morphological identification of SC cell types, neurobiotin was electroporated into the cell after recording visual responses. Positive current pulses were applied at $2 \mathrm{~Hz}$ with a $50 \%$ duty cycle and increasing amplitude $(0.5-8 \mathrm{nA})$ until the recorded cell began to fire action potentials entrained to 


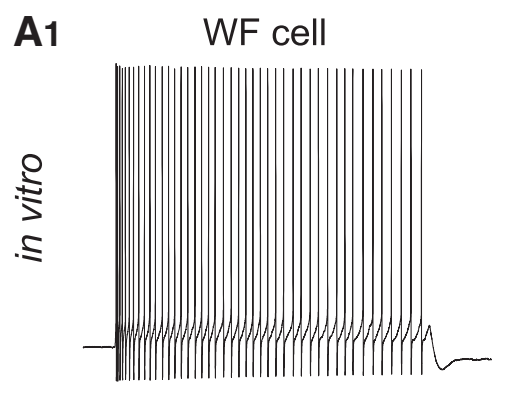

A2

Non-WF Cell

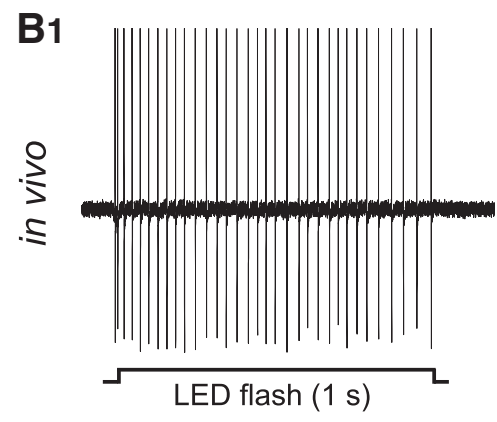

B2

Figure 1. Optogenetic identification of WF cells in Ntsr-GN209-Cre $\times$ Ai32 mice. $A$, Representative examples of intracellularly recorded responses to blue light in WF cells ( $\boldsymbol{A} \mathbf{1})$ and non-WF cells (in this case, a stellate cell; $\boldsymbol{A}$ ) in vitro. $\boldsymbol{B}$, Same as $\boldsymbol{A}$ for example cells recorded extracellularly in vivo. Spikes in $\boldsymbol{B} 1$ are truncated.

the current steps. Mice were perfused and parasagittal sections $(50 \mu \mathrm{m})$ containing the right $\mathrm{SC}$ were cut with a vibratome. Neurobiotin cell fills were visualized with Alexa Fluor 488- or Alexa Fluor 594-conjugated streptavidin and imaged with a Zeiss confocal microscope.

Cell type identification. WF and other SC cell types were identified in vitro via their distinct electrophysiological properties as described previously (Gale and Murphy, 2014). Cells directly relevant to this study were combined with a larger dataset of 886 sSC neurons. Eleven electrophysiological parameters were calculated for each cell and hierarchical clustering into four groups was performed using Euclidean distance in 11dimensional space and Ward's linkage criterion.

Similarly, WF and horizontal cells were identified in vivo via clustering in eight-parameter morphological space as described previously (46 WF and 37 horizontal cells; Gale and Murphy, 2014) or by responses to blue light emitted from an optical fiber in the recording electrode in transgenic mice with cell-type-specific expression of ChR2 (Ntsr1-GN209Cre $\times$ Ai32 mice for 68 WF cells and VGAT-ChR2 mice for 41 horizontal cells; see Results and Fig. 1).

Data analysis. Comparing the response of a cell to stationary or quickly moving stimuli versus slowly moving stimuli is nontrivial because the stimulus is changing for a longer duration in the latter case and therefore typically elicits a greater total number of spikes. Because responses to the onset and/or offset of stationary stimuli or to quickly moving stimuli are brief, we chose to define each cell's response as the peak of the trialaveraged spike density function for each stimulus. Spike density functions were calculated by convolving spike times for each trial with a Gaussian filter (SD, $20 \mathrm{~ms}$ ) and then averaging across trials for each stimulus type. Using a longer window duration to calculate response magnitude increases the movement selectivity of WF cells and decreases their preferred speed (Gale and Murphy, 2014).

Best/preferred size or speed was defined as the spot diameter or speed that elicited the strongest response. Size or speed tuning width was the integral of the size or speed tuning curve divided by its peak. A surround suppression index was calculated as the difference between the maximum response and the response to the largest spot $\left(32^{\circ}\right.$ diameter $)$ divided by the maximum response. Movement selectivity index was the difference between the maximum response to a moving stimulus (optimal size and speed) and the maximum response to a stationary stimulus divided by the sum of these responses.
Elliptical 95\% confidence regions in spike baseline/onset potential space (see Fig. 6B,E) were estimated using the principal components for all spikes from each cell in this space. The two eigenvalues accounting for the most variance determined the length of the major and minor ellipse axes (a normal distribution of the same variance was used to translate these values to a 95\% confidence level) and the corresponding eigenvectors determined the orientation of the axes. The calculated confidence regions contained $92-100 \%$ of spikes for each cell.

To compare size tuning width, surround suppression, speed tuning width, and movement selectivity for laser on and laser off conditions (for ArchT and control experiments shown in see Fig. $8 C$ ), we performed two-sided Wilcoxon signedrank tests. Statistical significance was considered $p<0.05 / 4$ for the four comparisons for each population (ArchT and control).

\section{Results}

\section{Identification of WF cells}

The sSC contains at least four cell types with distinct morphological and physiological properties. In previous work and for much of this study, WF and other cells were electroporated with neurobiotin after characterization of visual responses and distinguished according to quantitative morphological properties (Gale and Murphy, 2014). For some experiments in this study, we used an alternative method to target WF cells directly. Ntsr1-GN209-Cre mice, in which Crerecombinase is expressed in WF but not other sSC cell types, were crossed to Ai32 mice to enable Cre-dependent ChR2 expression (Madisen et al., 2012; Gerfen et al., 2013; Gale and Murphy, 2014).

To confirm that WF cells express ChR2 selectively in Ntsr1GN209-Cre $\times$ Ai32 mice, we first recorded responses of WF and other SC cell types to ChR2 activation in brain slices. WF cells exhibited sustained spiking for the full duration of stimulation with blue light ( $n=6$; Fig. 1A1). All other cells spiked once at the onset of light or did not spike at all ( $n=3$ narrow-field, $n=5$ stellate, and $n=4$ horizontal cells; Fig. 1A2); these responses, but not those of WF cells, were abolished by coapplication of the iontotropic glutamate receptor antagonists NBQX and AP5. Synaptic responses were not observed in non-WF cells when ChR2 was expressed in WF cells via virus injection in the sSC, so they likely originate from axons of Cre-expressing cells outside of the sSC (Gale and Murphy, 2014).

Similar to our observations in vitro, WF cells recorded in vivo (and identified post hoc by their morphology) showed sustained firing for the duration of stimulation with blue light $(n=7)$, whereas other cells spiked once at the onset of stimulation or did not respond ( $n=3$ narrow-field, $n=3$ stellate, and $n=2$ horizontal cells; Fig. $1 B)$. Therefore, sustained spiking in response to blue light enabled immediate and reliable identification of WF cells.

\section{WF cells respond most strongly to slowly moving objects}

We previously characterized the selectivity with which WF cells responded to stationary or moving bright spots of varying sizes on a dark background (Gale and Murphy, 2014). WF cells responded preferentially to a small subset of the stimuli presented-in particular, when the stimulus was small and moving slowly. Such stimuli mimic a limited subset of the stimuli 
that a mouse might encounter in the wild; for example, slow movement of a small, nearby object or faster movement of a larger, distant object.

The appearance and radial expansion of a dark spot may represent a more behaviorally relevant stimulus: the approach of a predator. How do WF cells respond to such stimuli? We presented expanding dark or light spots on a gray background that simulate an object approaching at constant speed; the expansion rate is a nonlinear function of the object size/speed ratio (Fig. 2A1). Like some cells that respond selectively to approaching objects in insects and pigeons (Sun and Frost, 1998; Gabbiani et al., 1999), the time of the peak response in WF cells was linearly related to the size/speed ratio of the approaching object corresponding to a particular angular size. Responses to dark objects were stronger than those to light objects of equal absolute contrast or lower contrast dark objects. However, responses to expanding spots were similar in strength or much weaker than responses to spots of optimal size and speed moving across the screen (Fig. 2A2). Therefore, approaching objects drive spike output in WF cells equally or less effectively as translational object motion.

Perhaps the most salient aspect of both expanding and translating stimuli is the contrast at the moving border between the stimulus and background. The selectivity with which neurons respond to visual stimuli can vary as a function of stimulus contrast (Levitt and Lund, 1997; Kapadia et al., 1999; Sceniak et al., 1999, 2002; Pack et al., 2005; Priebe et al., 2006). To investigate how size tuning and movement selectivity WF cells changes as a function of background luminance and object contrast, we compared responses to light spots on a dark background (Gale and Murphy, 2014) with responses to light and dark spots of varying contrast on a lighter (gray) background.

As for expanding stimuli, dark spots elicited stronger responses than light spots of equal absolute contrast. The preferred spot size for both dark and light spots on a gray background was larger than observed for light spots on a darker background (Fig. 2B). Regardless of the background luminance and stimulus contrast, however, the degree of surround suppression generated by the largest stimulus $\left(32^{\circ}\right.$ diameter) was the same (Fig. 2B2, inset). Speed tuning and movement selectivity were also unchanged (Fig. 2C,D) and similar results were obtained with lower contrast dark spots that elicited weaker responses. Therefore, the fundamental features of WF cell visual responses, including surround suppression and preferential responses to slowly moving stimuli, are preserved across a range of stimulus and background luminance levels.

The results presented thus far demonstrate that WF cells respond best to small, moving stimuli. However, some WF cells respond at least half-maximally to stimuli much larger than their preferred size. It was thus unclear whether WF cells might encode information about full-field motion in addition to object motion. To compare responses to object and background motion directly, we presented random checkerboard patterns consisting of $1^{\circ}$ light and dark squares that maintained the same luminance throughout the duration of the stimulus (Fig. 3A). A full-field "background" pattern was stationary or moved coherently in a particular direction. On some trials, we concurrently presented a smaller, independently moving "patch" of random checkerboard indistinguishable from the background. The patch is invisible except when moving differentially from background and appears to humans as a square that "pops out" (Frost et al., 1988).

WF cells responded vigorously to moving patches when the random checkerboard background was stationary; the patch size eliciting the largest response was typically between $4^{\circ}$ and $16^{\circ}$
(Fig. 3B). Therefore, object motion elicits responses in WF cells even when object texture and mean luminance do not differ from background. In comparison, responses to background (full-field) motion alone were rare and weak (Fig. 3C,D). Further, background motion strongly suppressed responses to motion of an optimally sized patch. The suppressive effect of background motion was weaker when patch motion was most distinct; that is, when there was a large difference in object/background speed and when the patch and background moved in opposite directions (Fig. 3C,D). These results suggest that WF cells most likely encode information about object motion rather than movement of the entire visual field (such as optic flow).

Together, our results show that WF cells respond most strongly to slowly moving objects. The remaining sections below explore the mechanisms underlying the visual response properties of WF cells. How do cells with broad dendritic arbors respond preferentially to stimuli covering a relatively small region of space? What mechanisms enhance responses to small, slowly moving stimuli and/or suppress responses to stimuli that appear suddenly, move quickly, or cover a large region of space?

\section{Distal dendritic branches of WF cells control spike output independently via strongly propagating dendritic spikes}

WF cells respond best to small, moving stimuli anywhere within a large region of visual space. The anatomical basis for their large spatial receptive field is a broad dendritic arbor sampling retinotopically organized input. The length and thin caliber of these dendrites, however, could significantly constrain the amount/ pattern of input necessary to trigger action potentials. In the absence of active amplification, postsynaptic potentials triggered by a small visual stimulus in a distal dendritic branch might be too severely attenuated to evoke an action potential at the axon (which originates near the soma). Previous studies suggest that sodium spikes initiated in the dendrites of WF cells can propagate strongly to the soma (Endo et al., 2008). Here, we build on this result by showing that: (1) restricted activation of any small, distal region of the dendritic arbor is sufficient to trigger somatic spikes; (2) separate branches of the dendritic arbor act independently to control spike output; and (3) spike output in response to visual stimuli is almost entirely driven by spikes initiated in dendrites.

Previous studies of dendritic spikes in WF cells relied on electrical stimulation of afferent axons or pressure ejection of glutamate over a large region (Endo et al., 2008). To confirm and extend these results, we used in vitro two-photon glutamate uncaging to investigate whether input restricted to a small, distal dendritic region can drive spike output in WF cells. Uncaging MNI-glutamate at 13-25 spots near a distal dendritic branch (375-475 $\mu \mathrm{m}$ from the soma; $n=9$ locations, 5 cells) triggered either a small, subthreshold depolarization $(0.9-1.9 \mathrm{mV})$ or one or more full-amplitude action potentials recorded at the soma (Fig. 4A1).

Action potentials evoked by glutamate uncaging differed markedly from those evoked by somatic current injection, emerging rapidly from the baseline potential without any noticeable proceeding depolarization (Fig. 4A2). This was true regardless of whether the baseline potential was near the resting potential or hyperpolarized $>15 \mathrm{mV}$ via somatic current injection. To quantify this observation, we calculated the potential at which the rate of change in membrane potential $(\mathrm{dV} / \mathrm{dt})$ crossed a threshold of $50 \mathrm{mV} / \mathrm{ms}$ (spike onset potential) and the average $\mathrm{dV} / \mathrm{dt}$ just preceding (0.5-1 ms) spike onset (prespike slope). Action potentials evoked by glutamate uncaging always had a 

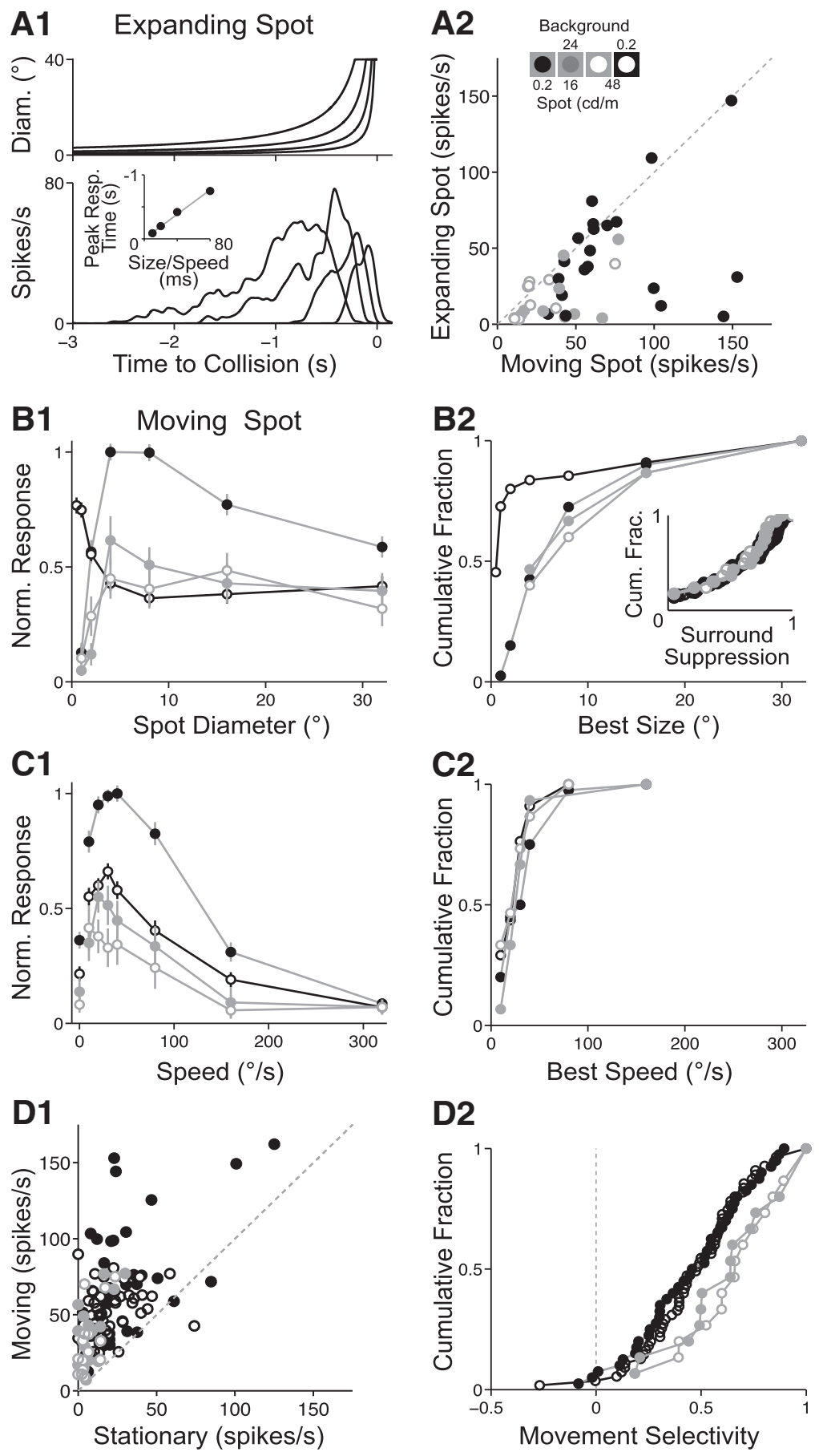

Figure 2. WF cells respond most strongly to small, slowly moving objects. $\boldsymbol{A}$, Comparison of responses to expanding and moving spots. The top panel of $\boldsymbol{A} \mathbf{1}$ shows expanding spot diameter as a function of time for simulated objects approaching at constant speed. Spot diameter depends on the ratio of the absolute size and approach speed of the object and the remaining time before expected collision (Gabbiani et al., 1999). Size/speed ratios were 10, 20,40, and $80 \mathrm{~ms}$. Spots were centered on the receptive field center of each cell and maximum/final spot diameter was limited to $40^{\circ}$. The bottom panel of $\boldsymbol{A} 1$ shows trial-averaged spike density functions for an example WF cell responding to objects with these size/speed ratios; the inset plots the peak response time for each size/speed ratio. A2 compares the maximum responses to expanding spots and spots moving across the receptive field center. Moving and expanding black spots on a gray background were presented to 20 cells, of which a subset were also shown white $(n=9)$ and/or dark gray spots $(n=10)$. $\boldsymbol{B}$, Change in size tuning as function of background and spot luminance. Black, white, or dark gray moving spots were presented on a gray background or white spots on a black background. $\boldsymbol{B} 1$ shows the mean response to spots of varying diameter moving through the receptive field center at $30 \%$. Responses were normalized to the maximum response across all sizes for each cell, averaged across cells, and then scaled relative to the average response magnitude for the four background-spot luminance combinations. Line and symbol color represent the relative background and spot luminance, respectively. $\mathbf{B} 2$ shows the distribution of best size and surround suppression index values for the populations. White spots on a black background were presented to 55 cells; separately, black spots on a gray background were presented to 40 cells of which a subset were also shown white $(n=15)$ and/or dark gray spots $(n=15)$ on the same background. C1, C2, Speed tuning as shown for size tuning in $\boldsymbol{B} \mathbf{1}$ and $\boldsymbol{B 2}$. The spot size that produced the largest response at $30 \%$ was used. Responses to the same-sized stationary stimulus are shown at $0 \%$. D. Comparison of maximum responses to optimal (size and speed) moving and stationary spots for each cell (D1) and the distribution of movement selectivity index values (D2). 

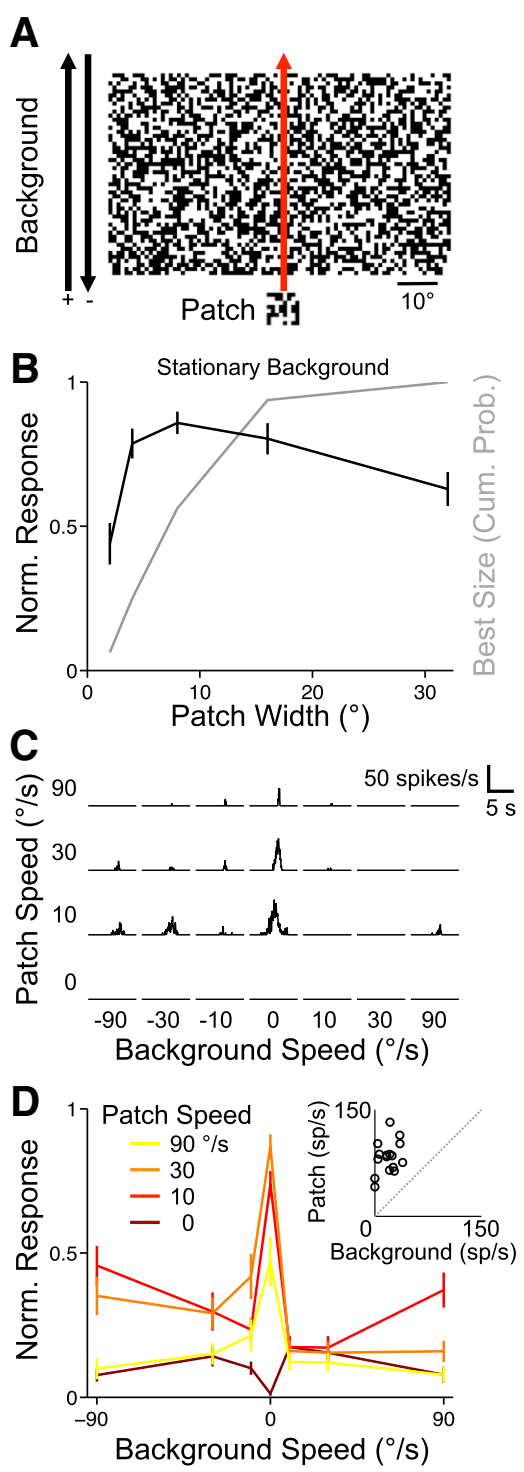

Figure 3. Responses of WF cells to relative motion of objects and background. $A$, Schematic example of a random checkerboard background pattern and a smaller, moving random checkerboard patch. Each checkerboard square was $1^{\circ}$ across and either 0.2 or $48 \mathrm{~cd} / \mathrm{m}^{2}$. The background pattern filled the entire screen and was stationary or moved across the screen in the same direction (positive speed) or opposite direction (negative speed) as the patch. $\boldsymbol{B}$, Mean response (black line) of $16 \mathrm{WF}$ cells to square patches of varying size moving over a stationary random checkerboard background. Responses were normalized to the maximum response across all sizes for each cell and then averaged. Error bars represent the SEM. The gray line shows the cumulative distribution of patch sizes that produced the largest response. C, Trial-averaged spike density functions for an example WF cell presented with various combinations of patch and background speeds. Patch size was optimized for each cell. $\boldsymbol{D}$, Mean response of $16 \mathrm{WF}$ cells to multiple combinations of patch and background speeds. Responses were normalized to the maximum response across all combinations for each cell and then averaged. Patch speed is represented by line color. The inset compares maximum responses to a patch alone (background speed $0 \% \mathrm{~s}$ ) and to background motion in the absence of a patch (patch speed $0 \% \mathrm{~s}$ ) for each cell.

onset potential within a few millivolts of the baseline potential and a prespike slope near zero (Fig. 4A3,A4). Similar results were observed for every distal uncaging site, including multiple distinct locations (up to three) on the same cell. These results suggest that synaptic input localized to any distal branch is sufficient to initiate strongly propagating dendritic spikes.

Similar spikes were observed in WF cells in response to endogenous glutamate released from the axons of RGCs expressing
ChR2 (Fig. 4B). Action potentials elicited in other SC cell types by the same stimulus, by comparison, exhibited depolarized onset potentials (similar to spikes driven by somatic current injection) and much faster prespike slopes (Fig. 4C). Therefore, unlike WF cells, spike output in other SC cell types appears to be driven by axosomatic integration of subthreshold EPSPs.

The strong coupling of dendritic and axosomatic spikes in WF cells prevented direct observation of dendritic spike potentials at the soma independently of a corresponding axosomatic spike; we did not observe smaller amplitude spikelets even when the soma was hyperpolarized $>15 \mathrm{mV}$. To separate dendritic and axosomatic spikes in WF cells, we added the sodium channel blocker QX-314 (2 mM) to the pipette internal solution. In this condition, somatic current injection evoked a single spike overshooting 0 $\mathrm{mV}$, but not sustained spiking (WF cells normally sustain spiking faster than 100 spikes/s) or smaller amplitude spikelets. Conversely, synaptic input provided by ChR2-expressing RGC axons evoked 10-20 mV spikelets or smaller subthreshold EPSPs (Fig. $4 D)$. As with dendritic spikes recorded with normal internal solution, spikelets could still be evoked when the soma was hyperpolarized $>15 \mathrm{mV}$ from rest. On some occasions, spikelets were sufficiently depolarizing to initiate an axosomatic spike. These results confirm that WF cell dendrites initiate strongly propagating spikes that, under normal conditions, reliably evoke axonal spike output.

Even if axosomatic integration of spatially distributed synaptic input is not essential for generating spike output in WF cells, it does not necessarily follow that each dendritic branch operates independently of others to influence spike output; spikes generated in one dendrite could propagate to other dendrites and influence subsequent spike initiation or propagation (Colbert et al., 1997; Golding and Spruston, 1998). To determine the degree to which action potentials back propagate in WF cells, we filled cells with the fluorescent $\mathrm{Ca}^{2+}$ indicator OGB1 and imaged dendritic $\mathrm{Ca}^{2+}$ signals associated with action potentials elicited by brief pulses of somatic current injection. Peak change in fluorescence $(\mathrm{d} F / F)$ differed little as we imaged increasingly distant locations from the soma ( $n=11$ cells, $2-9$ locations per cell 25-400 $\mu \mathrm{m}$ from the soma), suggesting that action potentials back propagate throughout the entire dendritic arbor (Fig. 5A). Nonetheless, the effect of back propagating action potentials (bAPs) on dendritic spike generation was brief. The interspike interval between bAPs and synaptically evoked spikes, which reflects both the interval between bAPs and ChR2 stimulation ("pulse interval") and the synaptic response latency, was $\sim 7 \mathrm{~ms}$ for the shortest pulse interval that reliably evoked dendritic spikes ( $2 \mathrm{~ms}$ pulse interval plus 5 ms response latency; Fig. $5 B$ ). The abbreviated influence of bAPs on dendritic spike initiation ensures that dendritic spiking in each dendritic branch occurs largely independently of spiking in other branches.

Previous bouts of synaptic input might also influence the ability of WF cell dendrites to generate spikes. In WF cells of the avian optic tectum, for example, strong and prolonged (lasting seconds) synaptic depression was proposed to underlie phasic signal transduction at inputs to an individual dendritic branch and therefore selective responses to stimuli that move across several branches (Luksch et al., 2004). However, in mouse WF cells, we did not observe this powerful synaptic depression. In our experiments, a broad swath of ChR2expressing retinal axons was simultaneously activated by light pulses delivered through the microscope objective. Dendritic spikes were reliably evoked by sequential light pulses separated by as little as 20 $\mathrm{ms}$ in all WF cells (Fig. 5C). 


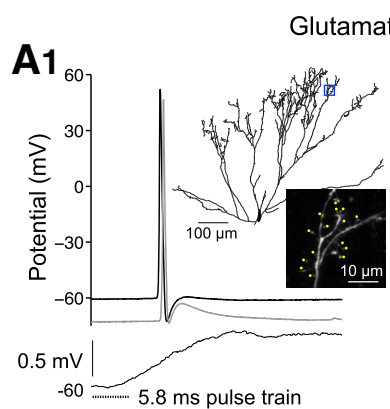

A2

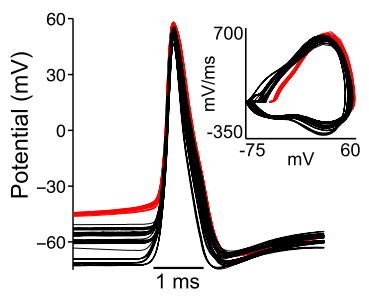

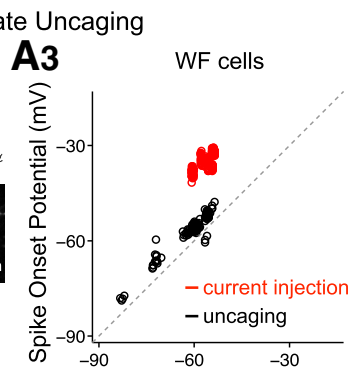

A4

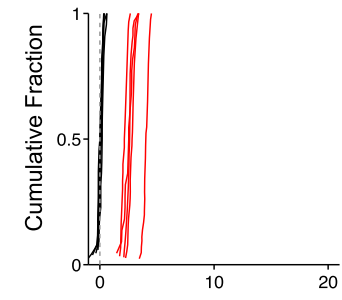

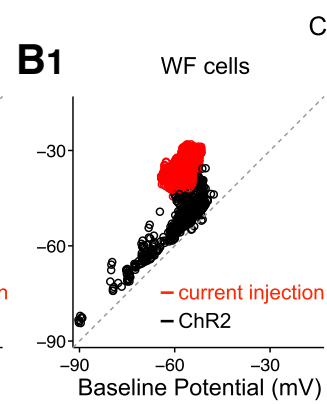

B2

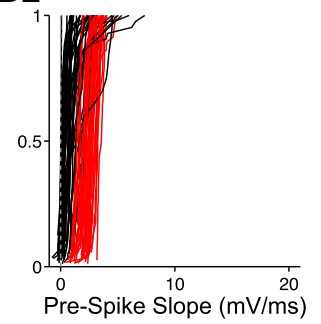

ChR2 in Retinal Ganglion Cell Axons

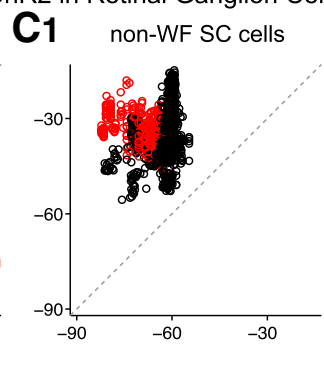

$\mathrm{C}_{2}$

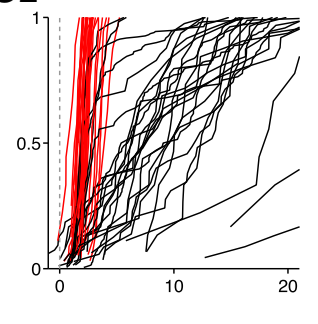

WF cells

(QX314 internal)

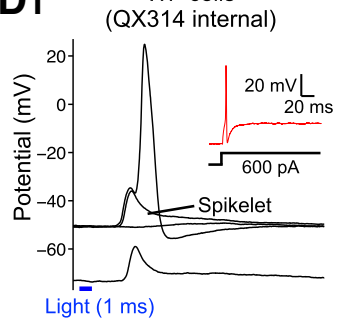

\section{D2}

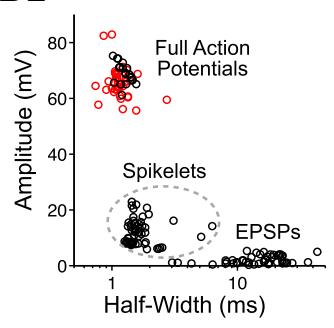

Figure 4. Synaptic input evokes strongly propagating dendritic spikes in WF cells. A1, Example suprathreshold and subthreshold responses to glutamate uncaging at the 15 yellow spots shown on the dendrite image. The small red box over the full cell tracing indicates the location of this image. Uncaging laser pulses were $0.2 \mathrm{~ms}$ in duration with $0.2 \mathrm{~ms}$ between pulses. The subthreshold response is the average of 10 trials in which no spikes were observed. For the gray trace, the soma was was hyperpolarized via current injection. $\mathbf{A 2}$, All spikes evoked by uncaging (black) or, for comparison, somatic current injection (red) in this cell. A3, A4, Spike onset potential and prespike slope values for all spikes elicited by glutamate uncaging (black) or current injection (red) in five WF cells. Current injection amplitude was at or slightly stronger than the minimum to evoke action potentials. Baseline potential is resting potential or the holding potential for trials in which cells were hyperpolarized by somatic current injection. $\boldsymbol{B} \mathbf{1}, \boldsymbol{B} 2$, Same as $\boldsymbol{A} \mathbf{3}$ and $\boldsymbol{A} \mathbf{4}$ for spikes driven by ChR2 activation in RGC axons ( $n=38$ WF cells). C1, C2, Same as $\boldsymbol{B} \mathbf{1}$ and $\boldsymbol{B} \mathbf{2}$ for other sSC cell types ( $n=7$ narrow field, $n=6$ stellate, and $n=15$ horizontal cells). The prespike slope distributions of two cells extending up to $40 \mathrm{mV} / \mathrm{ms}$ are not fully shown. $\boldsymbol{D}$, Example responses to ChR2 stimulation in a WF cell recorded with the sodium channel blocker QX-314 (2 mM) in the pipette internal solution (D1). The inset shows an example response to current injection. D2 shows for five WF cells the amplitude and width at half amplitude of all responses to ChR2 activation or current injection.

\section{Visual responses in WF cells are nearly exclusively driven by dendritic spikes}

To what degree does dendritic action potential generation underlie visual responses of WF cells in vivo? To answer this question, we analyzed spikes evoked by visual stimuli during whole-cell recordings of WF and, for comparison, other sSC cell types in vivo. In WF cells $(n=7)$, baseline subthreshold membrane fluctuations were small (SD, $0.5-0.8 \mathrm{mV}$ ) and spikes evoked by visual stimuli emerged from an otherwise little changed or slightly hyperpolarized potential (Fig. 6A). Phasic inhibitory potentials were observed in response to the onset and/or offset of a stationary spot, particularly when the spot was large. Similar to spikes elicited by glutamate uncaging on distal dendrites of WF cells in vitro (Fig. $4 B$ ), spike onset potentials were close to the baseline potential (Fig. $6 B$ ) and prespike slopes were near zero (Fig. 6C). Therefore, nearly all visually driven spikes in WF cells appear to initiate in dendrites.

In comparison, in non-WF cell types recorded in the $\operatorname{sSC}(n=$ 10 horizontal and $n=5$ stellate cells), subthreshold membrane potential fluctuations before visual stimuli were larger (SD, 1.2$3.9 \mathrm{mV}$ ) and during visual stimuli action potentials emerged on top of large, slow depolarizing responses (Fig. $6 D$ ). Similar to synaptic responses of these cell types in vitro (Fig. 4D), spike onset potentials were several millivolts above the baseline potential before visual stimulus presentation (Fig. $6 E$ ) and prespike slopes were positive (Fig. $6 F$ ).

\section{Inhibitory SC neurons contribute to surround suppression and movement selectivity in WF cells}

Dendritic spike generation in WF cells facilitates responses to small objects located anywhere within a large region of visual/ dendritic space, but this leaves unanswered why responses to larger stimuli are relatively weak. Similarly, sequential activation of individual dendrites does not explain movement selectivity in mouse WF cells (Luksch et al., 2004). Indeed, moving stimuli elicit more (total) spikes than stationary stimuli in both WF cells and other SC cell types. WF cells are unique in exhibiting movement selectivity at very short time scale as well (briefer than required for slowly moving stimuli to activate several branches; Gale and Murphy, 2014).

Two observations led us to consider the possibility that size tuning and movement selectivity in WF cells is generated by suppressing responses to large and/or suddenly appearing stationary stimuli rather than enhancing responses to small and/or slowly moving stimuli. First, the visual stimulus features that most effectively elicited responses in SSC GABAergic neurons (Endo et al., 2003; Gale and Murphy, 2014; "horizontal cells") were the opposite of those to which WF cells responded. Whereas WF cells responded most strongly to relatively small and slowly moving stimuli, horizontal cells responded best to the sudden appearance or brisk motion of larger stimuli (Fig. 7A-C). Also unlike WF cells, horizontal cells responded strongly to full-field, random checkerboard patterns, particularly when stimulus motion was fast (Fig. 7D). Second, horizontal cells inhibit WF cells directly. In SC slices from Gad2-Cre mice in which we injected virus coding for Cre-dependent ChR2 expression, brief flashes of blue light elicited spikes in horizontal cells and IPSPs in WF cells (Fig. 8A).

The opposing selectivity of visual responses of WF and horizontal cells suggests that horizontal-cell-mediated inhibition might constrain the stimuli to which WF cells respond. To test the influence of horizontal cell activity on size tuning and movement selectivity in WF cells directly, we recorded visual responses of WF cells while optogenetically inhibiting horizontal cells. Virus enabling Credependent ArchT (Han et al., 2011) expression was injected into the 

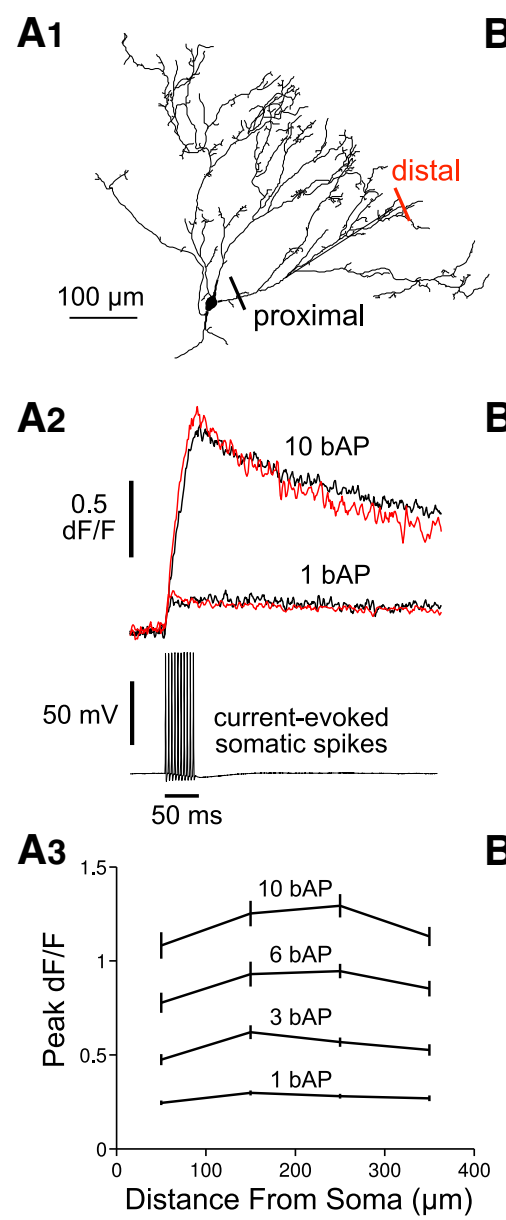

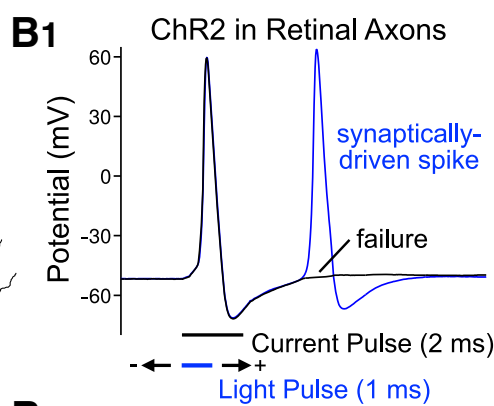

B2
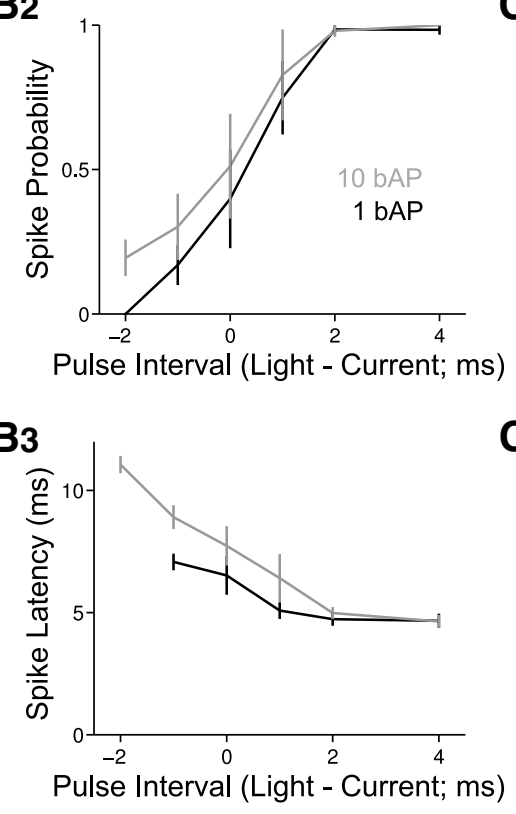

C2

C1
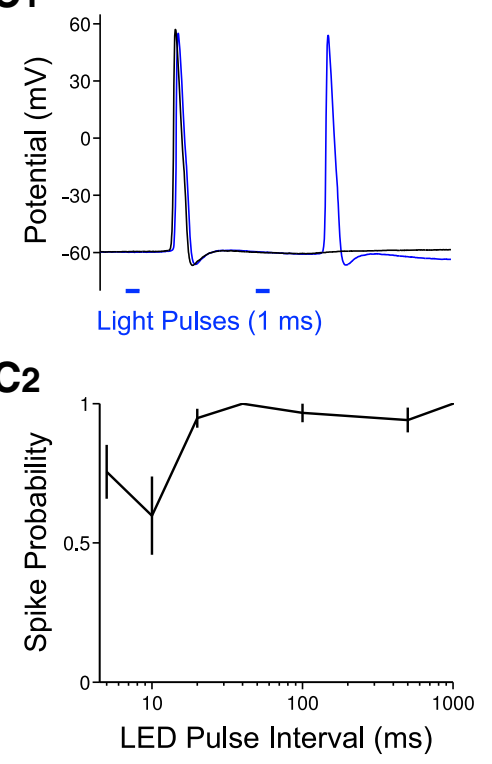

C3

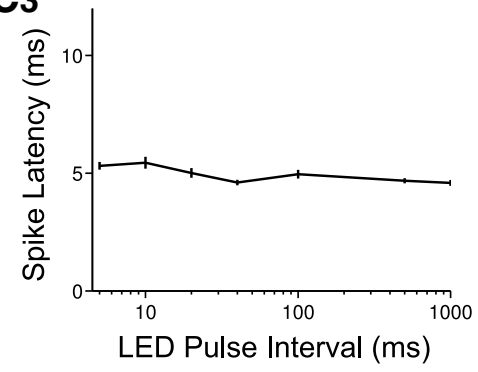

Figure 5. Proceeding somatic spikes and synaptic input have a limited effect on dendritic spike initiation. $\boldsymbol{A}$, Dendritic $\mathrm{Ca}^{2+}$ signals after somatic action potentials. $\boldsymbol{A 2}$, $\mathrm{d} F / F$ in response to bAPs evoked by somatic current injection ( $2 \mathrm{~ms}$ pulses) for the line-scan locations indicated with red lines in $\boldsymbol{A} 1$. For trials with multiple action potentials, the start-to-start interval between current pulses was $5 \mathrm{~ms}$. A3, Peak dF/F values spatially binned and averaged across 11 cells. $\boldsymbol{B}$, Activation of ChR2 in RGC axons (1 ms LED pulse) at variable latency relative to one or the last of 10 action potentials elicited at the soma via current injection. B1, Overlaid examples in which the LED pulse did (blue) or did not (black) evoke a dendritic spike (the current pulse elicited a spike on both trials). In these examples, the interval between the start of the LED and current pulses ("pulse interval") was 0 ms. B2, Mean spike probability in response to ChR2 activation as a function of the pulse interval. Negative intervals indicate the LED pulse started before the current pulse. B3, Mean latency of spikes elicited by ChR2 activation as a function of the pulse interval for 5 WF cells. C, Response of WF cells to paired-pulse stimulation of ChR2-expressing retinal axons. (1, Overlaid examples in which the second LED pulses did (blue) or did not (black) evoke a dendritic spike. C2, Mean spike probability in response to the second pulse for varying pulse interval for 7 WF cells. C3, Mean latency of spikes elicited by the second pulse.

sSC of Gad2-Cre mice (Fig. 8B,C). Cell-type specificity of ArchT expression was confirmed in brain slice experiments. ArchT activation hyperpolarized 13/14 horizontal cells (Fig. 8B) and had no effect on the membrane potential of other cell types ( $0 / 10 \mathrm{WF}, 0 / 8$ narrowfield, and 0/14 stellate cells).

For in vivo experiments, ArchT was activated via $594 \mathrm{~nm}$ light emitted from an etched optical fiber positioned inside the recording electrode $\sim 300 \mu \mathrm{m}$ from the tip. Visual responses in WF cells were stronger on randomly interleaved trials in which ArchT was activated in horizontal cells for the duration of the visual stimulus ("laser on") relative to control trials ("laser off"). The relative increase in response strength was particularly pronounced for stimuli that were large and/or stationary (Fig. 9A,B); accordingly, size tuning broadened and movement selectivity decreased (Fig. 9C).

In some cases, activating ArchT in horizontal cells unveiled WF cell responses to the onset or offset of stationary stimuli that did not exist under control conditions; nonetheless, in all cells, the component of the response that was strongest ("on" or "off") did not change. Some cells recorded with a black background also exhibited an extended response to the offset of large, bright stimuli (Fig. 9A3); these responses were more common when hori- zontal cells were inhibited ( $4 / 8$ cells), but also occurred in control conditions ( $1 / 8$ cells). Delayed responses to the offset of large stimuli are also observed in other cell types in the sSC (unpublished observation) and may reflect disinhibition after strong activation of the receptive field surround.

Across the population of WF cells, activation of ArchT in horizontal cells substantially weakened surround suppression (mean $90 \%$ increase in size tuning width and 0.36 absolute decrease in surround suppression index; $p<0.01$ ); in most cases, the stimulus size that elicited the strongest response also increased (5/8 cells for each background luminance). Increased responses to stationary stimuli relative to moving stimuli resulted in a 0.36 absolute decrease in movement selectivity index $(p<$ 0.001). In comparison, activation of ArchT only moderately broadened speed tuning ( $40 \%$ increase in speed tuning width; $p<0.01)$ and, in control experiments in which there was no ArchT expression in the SC, laser stimulation had no effect on visual responses (Fig. 9C, far right). Therefore, tuned inhibition from horizontal cells suppresses responses of WF cells to large stimuli and to the sudden appearance/disappearance of stationary stimuli. 

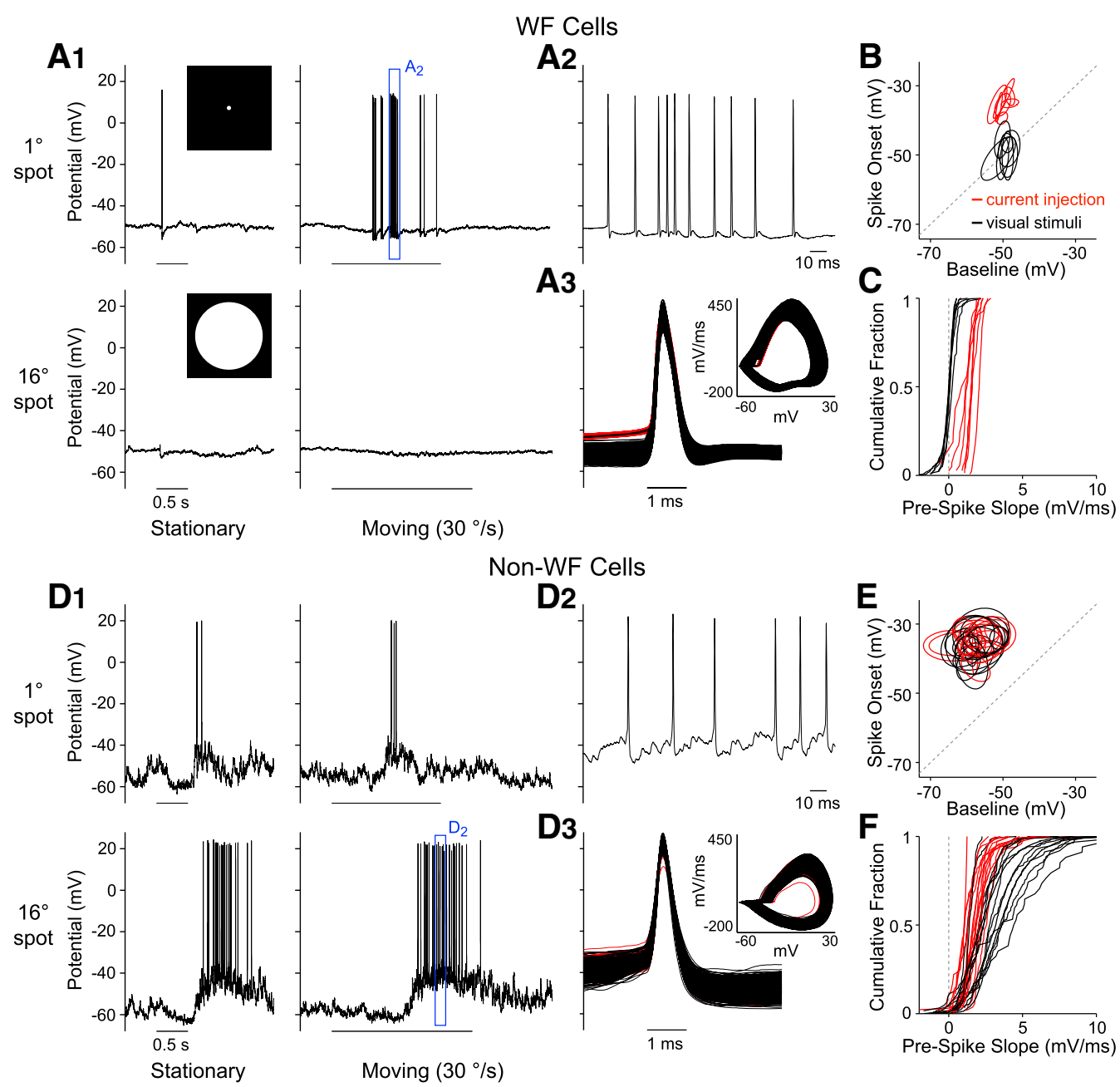

Figure 6. Membrane potential responses to visual stimuli in WF and other sSC cells. Background and spot luminance were 0.2 and $48 \mathrm{~cd} / \mathrm{m}^{2}$, respectively. A, Example in vivo whole-cell recording from a WF cell showing responses to stationary and moving $\left(30^{\circ} / \mathrm{s}\right)$ spots $\left(1^{\circ}\right.$ or $16^{\circ}$ diameter). Horizontal scale bars indicate the time during which the stimulus was on the screen. $\boldsymbol{A} 2$, Expanded version of the trace enclosed by a blue box in $\boldsymbol{A}$ 1. $\boldsymbol{A}$, All spikes elicited by visual stimuli (black) or somatic current injection (red) in this cell. $\boldsymbol{B}, \boldsymbol{C}$, Spike onset potential $(\boldsymbol{B})$ and prespike slope $(\boldsymbol{C})$ for 7 WF cells. Ellipses in $\boldsymbol{B}$ represent $95 \%$ confidence regions for each cell (see Materials and Methods). D1-D3, Same as $\boldsymbol{A}$ 1-A3 for an example horizontal cell. $\boldsymbol{E}, \boldsymbol{F}$, Same as $\boldsymbol{B}$ and $\boldsymbol{C}$ for 10 horizontal and five stellate cells.

\section{Discussion}

Response selectivity is a fundamental property of sensory system neurons. Here, our results demonstrate how intrinsic properties and local synaptic input contribute to response selectivity of sSC neurons signaling object motion. Small, slowly moving objects trigger strongly propagating dendritic spikes in WF cells. Therefore, stimuli anywhere within the broad spatial receptive field of WF cells can reliably generate spike output in the absence of "summing" input from multiple dendrites at the soma. The range of stimuli that can trigger spikes is constrained by local inhibition from horizontal cells, which respond best to the sudden appearance or rapid motion of large stimuli. Other mechanisms (discussed below) also likely contribute to selectivity of visual responses in WF cells.

Strong propagation of dendritic spikes in WF cells enables spatially restricted synaptic input to reliably trigger axonal spike output. This highly localized synaptic integration is the primary, and perhaps exclusive, mechanism by which spike output is determined in response to physiological stimuli in WF cells. This mode of operation differs from neurons in which weakly propagating spikes contribute variable depolarization at the soma that can either trigger action potentials or summate with input from other dendrites (Golding and Spruston, 1998; Müller et al., 2012). Even relatively strongly propagating dendritic spikes in other neurons can fail to evoke a somatic spike when the soma is hyperpolarized by current injection or inhibitory synaptic input (Chen et al., 1997; Oesch et al., 2005; Sun et al., 2014; Trenholm et al., 2014). We did not observe spikelets suggestive of dendritic spike propagation failures in WF cells even when the soma was substantially hyperpolarized (we cannot, however, rule out propagation failures in the most distal dendritic branches; Sivyer and Williams, 2013). WF cells are most similar to globus pallidus neurons in which input targeting distal dendrites evokes all-ornone, strongly propagating dendritic spikes (Hanson et al., 2004).

Inhibition of horizontal cells, which prefer large, quickly moving stimuli, had a strong effect on size tuning in WF cells, but only moderately broadened their speed tuning (Fig. 9B2,C2). One possible explanation is that the excitatory input that WF cells receive is broadly size tuned but relatively more narrowly tuned for (slow) speed. In this scenario, horizontal cell inactivation could strongly disinhibit WF cells during presentation of quickly moving stimuli but, in the absence of strong excitatory input, have little impact on their spike rate. 
A potential mechanism underlying tuning for slow speeds in WF cells is that spikes initiated in one dendrite backpropagate to other dendrites in the line of object motion and diminish the probability of spike generation; slowly moving objects would evade this effect more than quickly moving objects. The brief refractory period that we measured, however, suggests that this is an unlikely explanation for speed tuning. The magnification factor of the mouse sSC retinotopic map is $\sim 60^{\circ}$ or $80^{\circ} / \mathrm{mm}$ for elevation and azimuth, respectively (Cang et al., 2008). WF cells respond poorly to stimuli moving faster than $100^{\circ} / \mathrm{s}$; at this speed, visual stimuli move just $0.7^{\circ}$ through visual space (approximately the resolution of mouse vision) represented by $<12 \mu \mathrm{m}$ of the $\mathrm{sSC}$ retinotopic map during the relative refractory period of $7 \mathrm{~ms}$. The dendritic arbor of WF cells, by comparison, extends nearly $1 \mathrm{~mm}$ across the retinotopic map. A more likely possibility is that the range of object speeds to which WF cells respond is limited by characteristics of their retinal input.

We also cannot rule out that WF cells to some degree "inherit" other characteristics of their response selectivity from retinal or cortical input. Indeed, the powerful role of local inhibition in generating response selectivity in WF cells contrasts with other visual system circuits in which selectivity is largely determined by biases in the excitatory input that each cell receives rather than tuned inhibitory input (Bock et al., 2011; Isaacson and Scanziani, 2011; Katzner et al., 2011; Ko et al., 2011). RGCs that are tuned to small stimuli and suppressed by global motion may influence the receptive field properties of WF cells; however, these cells differ from WF cells in their robust responses to the onset and offset of stationary stimuli and it is not known which sSC cell types they target (Olveczky et al., 2003; Zhang et al., 2012). WF cells, like all sSC cell types other than horizontal cells, are "speed tuned" in the sense that their preferred stimulus temporal frequency increases proportionally to increases in spatial frequency (Gale and Murphy, 2014). This property has not been reported in retina and may reflect cortical input (Priebe et al., 2006; Andermann et al., 2011). Cortical feedback might also regulate the magnitude and/or selectivity of responses in WF cells in a manner that depends on the relative impact of cortical synapses onto WF and horizontal cells (Zhao et al., 2014).

Our experiments do not rule out the possibility that changes in visual responses of WF cells during inhibition of horizontal cells were partially mediated by effects by indirect effects on other $\mathrm{SC}$ cell types and/or their anatomical targets. For example, at least in Figure 3.
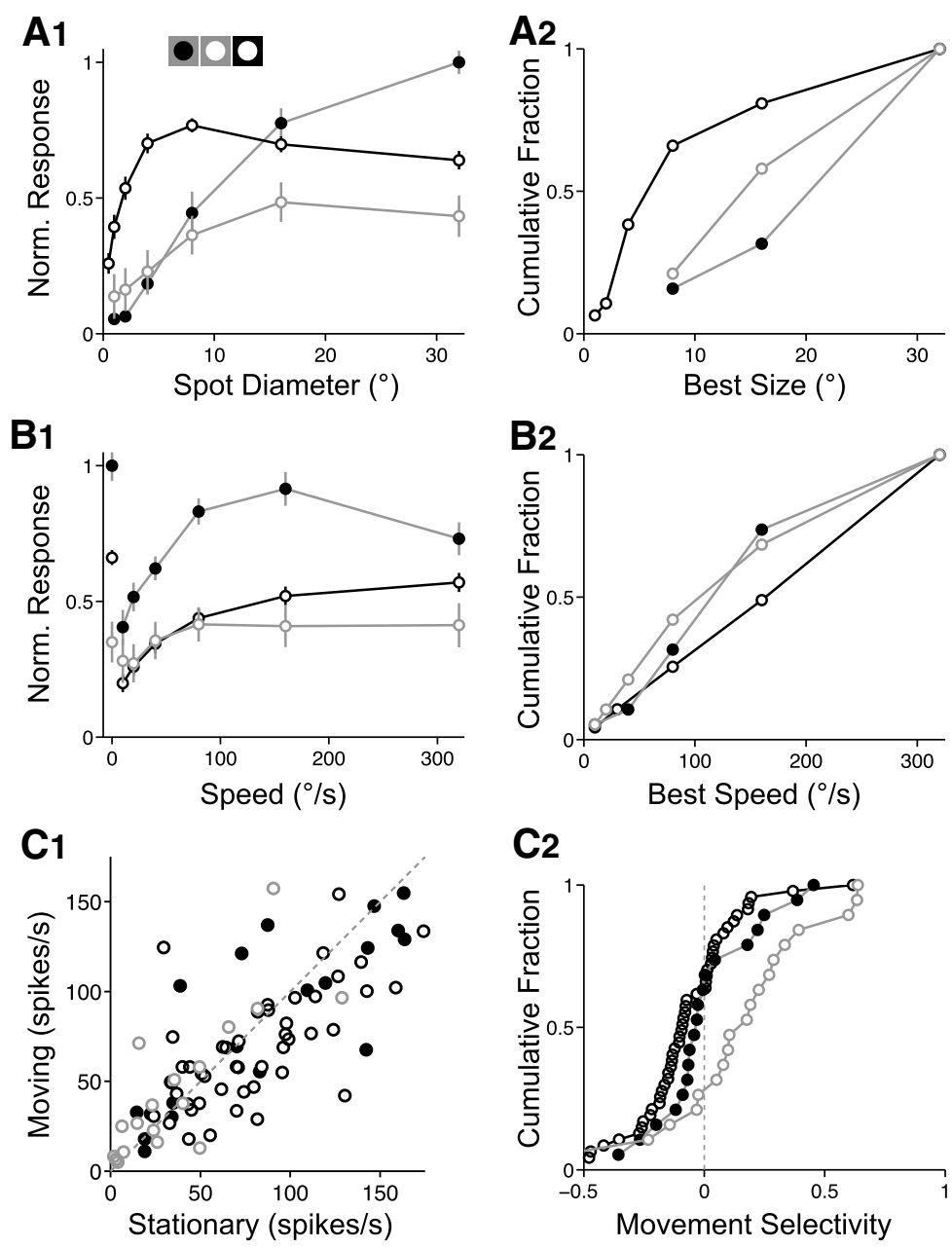

C2
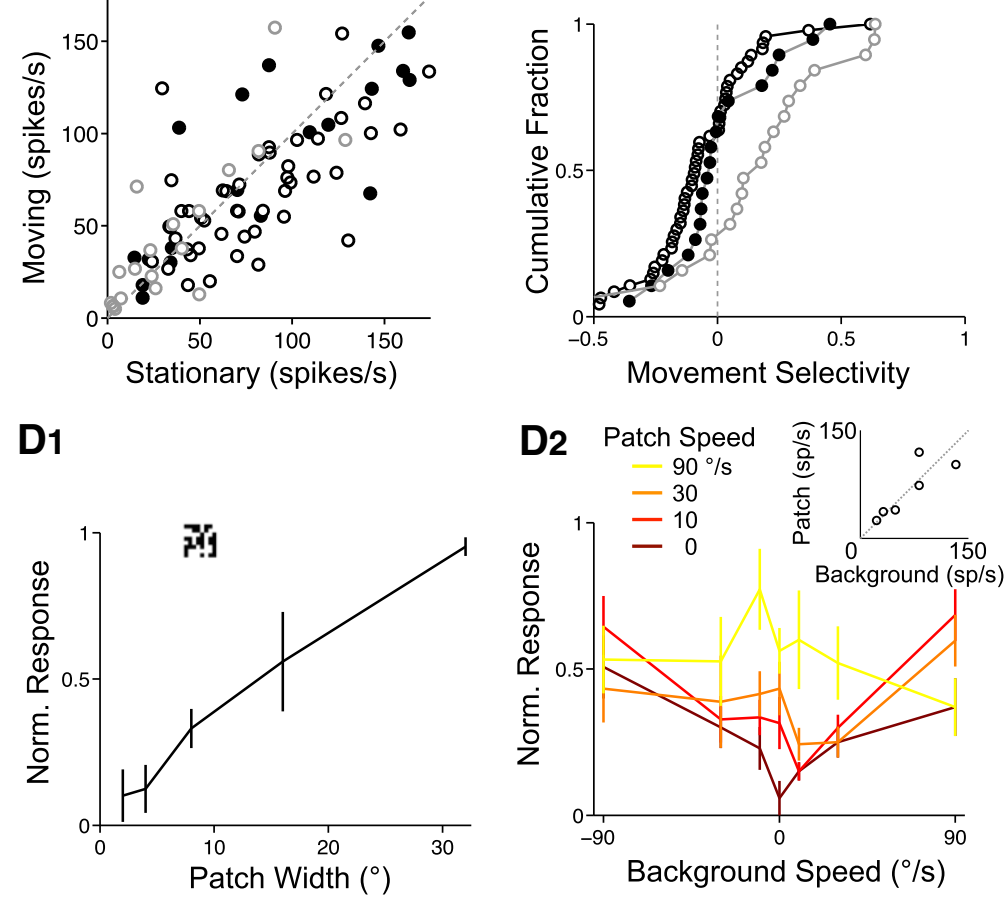

Figure 7. Size tuning, speed tuning, and movement selectivity in horizontal cells. $\boldsymbol{A}-\boldsymbol{C}$, Size tuning $(\boldsymbol{A 1}, \boldsymbol{A} 2)$, speed tuning $(B 1, B 2)$, and movement selectivity $(\boldsymbol{C} 1, C 2)$ in horizontal cells for different combinations of spot and background luminance, as shown for WF cells in Figure $2 B-D$. White spots on a black background were presented to 47 cells; black and white spots on a gray background were presented to 19 cells. $D$, Mean response of six horizontal cells to random checkerboard patches of varying size (D1) or to multiple combinations of patch and background speeds (D2), as shown for WF cells

some horizontal cells project to the lateral geniculate nucleus (Gale and Murphy, 2014; Bickford et al., 2015), which is a major source of excitatory input to visual cortical areas that target the sSC. More precisely targeted manipulation of horizontal-cellmediated inhibition of WF cells is required to resolve this issue. Together, however, the opposing selectivity of visual responses in horizontal and WF cells and the effects of suppressing horizontal cell activity both point to an important role for horizontal cells in shaping response selectivity in WF cells. 
A AAV Flex ChR2 2a GFP
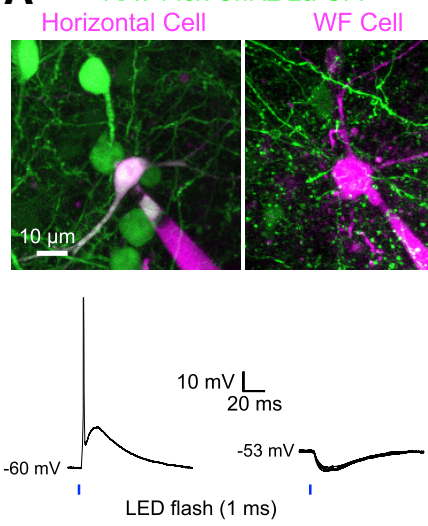
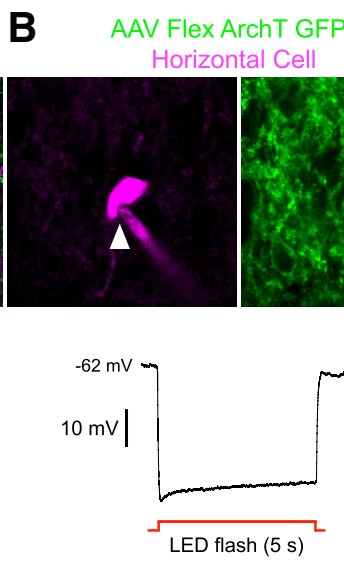

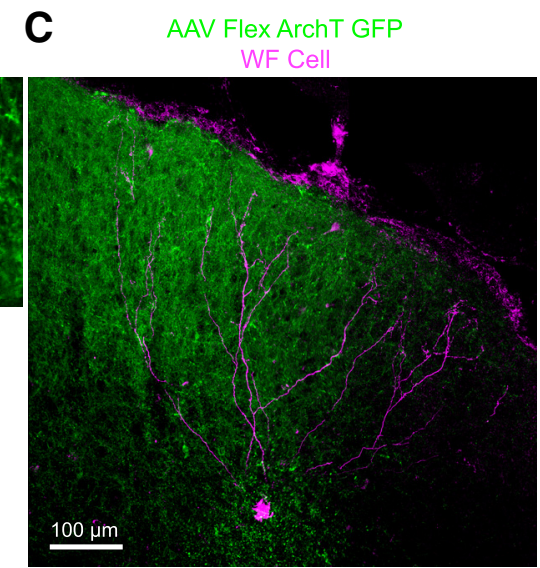

Figure 8. Horizontal cells inhibit WF cells. A, AAV-Flex-ChR2-2a-GFP was injected in the SC of Gad2 Cre mice and whole-cell recordings were performed in vitro. Left, z-projection of an example horizontal cell expressing GFP (green) and filled with Alexa Fluor 594 from the pipette internal solution (magenta). Right, Unlabeled WF cell from the same slice. Brief flashes of blue light elicited action potentials in the horizontal cell and IPSPs (six consecutive trials are shown) in the WF cell. B, Example horizontal cell recorded in vitro from a Gad2 Cre mouse injected with AAV-Flex-ArchT-GFP in the SC. The images show a single optical section; the white arrowhead indicates the same cell in each image channel. Orange light elicited a rapid and sustained hyperpolarization in this cell. C, Example WF cell recorded and filled in vivo from a Gad2 Cre mouse injected with AAV-Flex-ArchT-GFP in the SC. Visual responses from this cell (with and without ArchT activation in horizontal cells) are shown in Figure $9 A$.
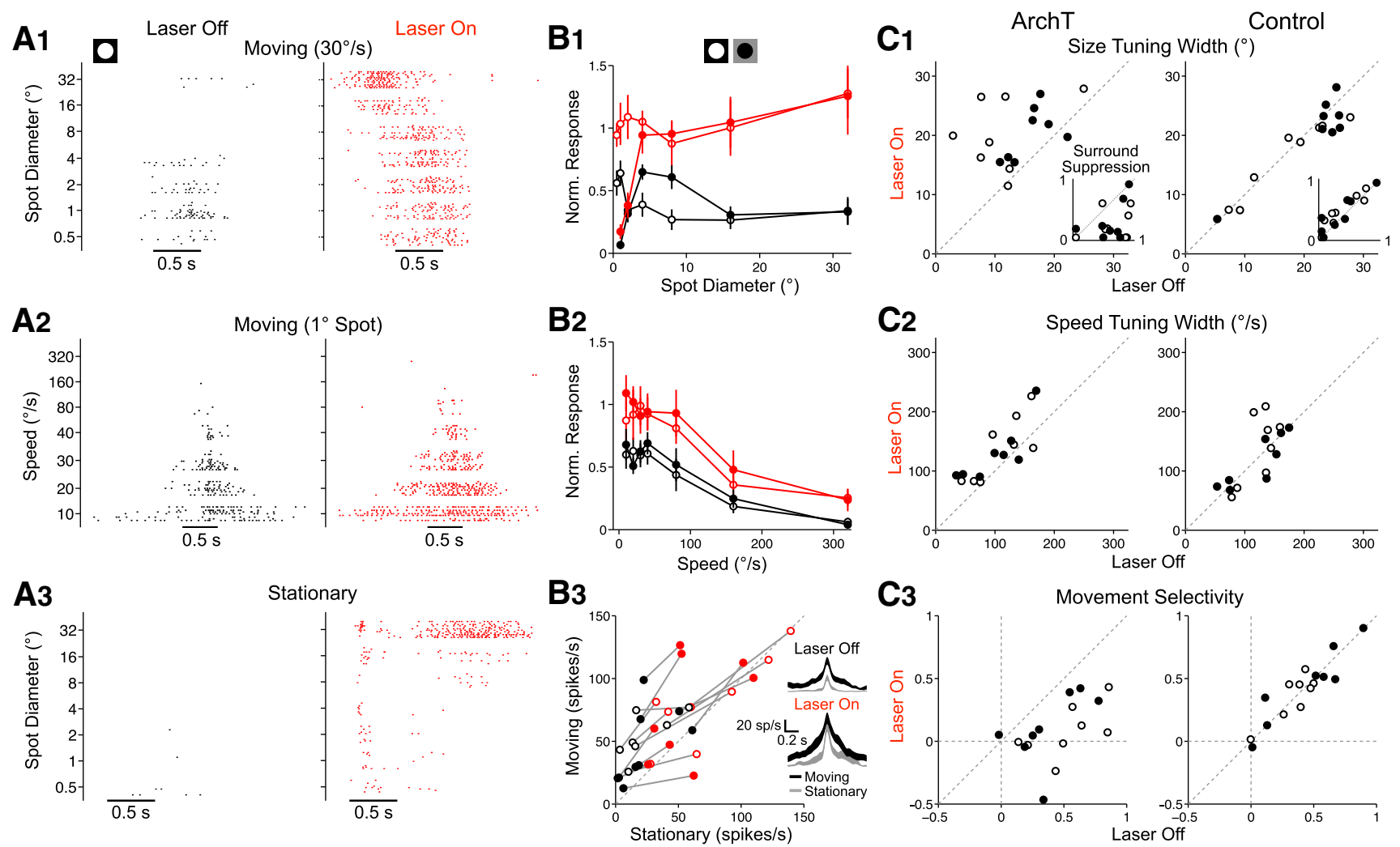

Figure 9. Suppressing horizontal cell activity alters visual response properties of WF cells. $A$, Responses of an example WF cell shown in Fig. $8 \mathrm{C}$ to stationary and moving spots of varying size and speed with or without laser activation of ArchT in horizontal cells. Background and spot luminance were 0.2 and $48 \mathrm{~cd} / \mathrm{m}^{2}$, respectively, for this cell. Each row of tick marks indicates spike times for one trial. Laser off (black) and laser on (red) trials were randomly interleaved during the experiment. Responses to moving stimuli $(\boldsymbol{A} \mathbf{1}, \boldsymbol{A} \mathbf{2})$ are aligned to the time at which the center of the spot crossed the receptive field center; the center of the $0.5 \mathrm{~s}$ scale bar indicates the time at which this occurred. Responses to stationary stimuli $(\boldsymbol{A} \boldsymbol{B})$ presented at the receptive field center are aligned to stimulus onset; the $0.5 \mathrm{sscale}$ bar indicates the time of the stimulus. $\boldsymbol{B}$, Mean size (B1) and speed (B2) tuning curves and comparison of the maximum responses to optimal (size and speed) moving and stationary spots (B3) with the laser on (red) or off (black). Eight WF cells were recorded with background and spot luminance of 0.2 and $48 \mathrm{~cd} / \mathrm{m}^{2}$, respectively (open symbols), and another eight WF cells were recorded with background and spot luminance of 24 and and $0.2 \mathrm{~cd} / \mathrm{m}^{2}$ (filled symbols). B2, For tuning curves, responses are normalized to the maximum response across all sizes and speeds for each cell with the laser off. The inset in B3 shows population spike density functions (mean \pm SEM) for the optimal stationary (gray) and moving (black) stimulus for each cell aligned by the time of the peak response. $\mathbf{C}$, Comparison of size tuning width (C) $)$, surround suppression ( $\mathbf{C}$, inset), speed tuning width (C2), and movement selectivity $(\mathbf{C} \mathbf{3})$ with the laser on or off for each cell recorded in experiments with ArchT (left) or control experiments without ArchT (right). 
WF cells project bilaterally to the lateral posterior nucleus of thalamus (LP), which is bidirectionally connected with visual cortex but receives little, if any, retinal input. In primates, inactivation of the pulvinar (LP homolog) strongly suppresses visual responses of cortical neurons (Purushothaman et al., 2012) and both LP or SC inactivation produce deficits in spatial attention (Lovejoy and Krauzlis, 2010; Zénon and Krauzlis, 2012; Zhou et al., 2016). In mice, LP neurons have large spatial receptive fields and may signal local divergences in self-generated global motion created by movement of external objects (Roth et al., 2016). By responding most strongly when the motion of object and background are the most distinct (Fig. 3), WF cells appear to be well suited to contribute to this computation. Object motion is a salient sensory cue that often signals the presence of other animals. Therefore, the detection of object motion by WF cells and their targets in LP may have a powerful influence on cortical circuits, spatial attention, and behavior.

\section{References}

Adesnik H, Bruns W, Taniguchi H, Huang ZJ, Scanziani M (2012) A neural circuit for spatial summation in visual cortex. Nature 490:226-231. CrossRef Medline

Andermann ML, Kerlin AM, Roumis DK, Glickfeld LL, Reid RC (2011) Functional specialization of mouse higher visual cortical areas. Neuron 72:1025-1039. CrossRef Medline

Bickford ME, Zhou N, Krahe TE, Govindaiah G, Guido W (2015) Retinal and tectal "driver-like" inputs converge in the shell of the mouse dorsal lateral geniculate nucleus. J Neurosci 35:10523-10534. CrossRef Medline

Bock DD, Lee WC, Kerlin AM, Andermann ML, Hood G, Wetzel AW, Yurgenson S, Soucy ER, Kim HS, Reid RC (2011) Network anatomy and in vivo physiology of visual cortical neurons. Nature 471:177-182. CrossRef Medline

Cang J, Wang L, Stryker MP, Feldheim DA (2008) Roles of ephrin-as and structured activity in the development of functional maps in the superior colliculus. J Neurosci 28:11015-11023. CrossRef Medline

Chen EY, Marre O, Fisher C, Schwartz G, Levy J, da Silviera RA, Berry MJ 2nd (2013) Alert response to motion onset in the retina. J Neurosci 33: 120-132. CrossRef Medline

Chen WR, Midtgaard J, Shepherd GM (1997) Forward and backward propagation of dendritic impulses and their synaptic control in mitral cells. Science 278:463-467. CrossRef Medline

Colbert CM, Magee JC, Hoffman DA, Johnston D (1997) Slow recovery from inactivation of $\mathrm{Na}+$ channels underlies the activity-dependent attenuation of dendritic action potentials in hippocampal CA1 pyramidal neurons. J Neurosci 17:6512-6521. Medline

Del Bene F, Wyart C, Robles E, Tran A, Looger L, Scott EK, Isacoff EY, Baier $\mathrm{H}$ (2010) Filtering of visual information in the tectum by an identified neural circuit. Science 330:669-673. CrossRef Medline

Endo T, Yanagawa Y, Obata K, Isa T (2003) Characteristics of GABAergic neurons in the superficial superior colliculus in mice. Neurosci Lett 346: 81-84. CrossRef Medline

Endo T, Tarusawa E, Notomi T, Kaneda K, Hirabayashi M, Shigemoto R, Isa T (2008) Dendritic Ih ensures high-fidelity dendritic spike responses of motion-sensitive neurons in rat superior colliculus. J Neurophysiol 99: 2066-2076. CrossRef Medline

Frost BJ (2010) A taxonomy of different forms of visual motion detection and their underlying neural mechanisms. Brain Behav Evol 75:218-235. CrossRef Medline

Frost BJ, Cavanagh P, Morgan B (1988) Deep tectal cells in pigeons respond to kinematograms. J Comp Physiol A 162:639-647. CrossRef Medline

Gabbiani F, Krapp HG, Laurent G (1999) Computation of object approach by a wide-field, motion-sensitive neuron. J Neurosci 19:1122-1141. Medline

Gabriel JP, Trivedi CA, Maurer CM, Ryu S, Bollmann JH (2012) Layerspecific targeting of direction-selective neurons in the zebrafish optic tectum. Neuron 76:1147-1160. CrossRef Medline

Gale SD, Murphy GJ (2014) Distinct representation and distribution of visual information by specific cell types in mouse superficial superior colliculus. J Neurosci 34:13458-13471. CrossRef Medline

Gerfen CR, Paletzki R, Heintz N (2013) GENSAT BAC cre-recombinase driver lines to study the functional organization of cerebral cortical and basal ganglia circuits. Neuron 80:1368-1383. CrossRef Medline

Golding NL, Spruston N (1998) Dendritic sodium spikes are variable triggers of axonal action potentials in hippocampal CA1 pyramidal neurons. Neuron 21:1189-1200. CrossRef Medline

Han X, Chow BY, Zhou H, Klapoetke NC, Chuong A, Rajimehr R, Yang A, Baratta MV, Winkle J, Desimone R, Boyden ES (2011) A high-light sensitivity optical neural silencer: development and application to optogenetic control of non-human primate cortex. Front Syst Neurosci 5:18. CrossRef Medline

Hanson JE, Smith Y, Jaeger D (2004) Sodium channels and dendritic spike initiation at excitatory synapses in globus pallidus neurons. J Neurosci 24:329-340. CrossRef Medline

Hunter PR, Lowe AS, Thompson ID, Meyer MP (2013) Emergent properties of the optic tectum revealed by population analysis of direction and orientation selectivity. J Neurosci 33:13940-13945. CrossRef Medline

Isaacson JS, Scanziani M (2011) How inhibition shapes cortical activity. Neuron 72:231-243. CrossRef Medline

Kapadia MK, Westheimer G, Gilbert CD (1999) Dynamics of spatial summation in primary visual cortex of alert monkeys. Proc Natl Acad Sci U S A 96:12073-12078. CrossRef Medline

Katzner S, Busse L, Carandini M (2011) GABAA inhibition controls response gain in visual cortex. J Neurosci 31:5931-5941. CrossRef Medline

Ko H, Hofer SB, Pichler B, Buchanan KA, Sjöström PJ, Mrsic-Flogel TD (2011) Functional specificity of local synaptic connections in neocortical networks. Nature 473:87-91. CrossRef Medline

Levitt JB, Lund JS (1997) Contrast dependence of contextual effects in primate visual cortex. Nature 387:73-76. CrossRef Medline

Lovejoy LP, Krauzlis RJ (2010) Inactivation of primate superior colliculus impairs covert selection of signals for perceptual judgments. Nat Neurosci 13:261-266. CrossRef Medline

Luksch H, Khanbabaie R, Wessel R (2004) Synaptic dynamics mediate sensitivity to motion independent of stimulus details. Nat Neurosci 7:380-388. CrossRef Medline

Madisen L, Mao T, Koch H, Zhuo JM, Berenyi A, Fujisawa S, Hsu YW, Garcia AJ 3rd, Gu X, Zanella S, Kidney J, Gu H, Mao Y, Hooks BM, Boyden ES, Buzsáki G, Ramirez JM, Jones AR, Svoboda K, Han X, Turner EE, Zeng H (2012) A toolbox of Cre-dependent optogenetic transgenic mice for light-induced activation and silencing. Nat Neurosci 15:793-802. CrossRef Medline

Müller C, Beck H, Coulter D, Remy S (2012) Inhibitory control of linear and supralinear dendritic excitation in CA1 pyramidal neurons. Neuron 75: 851-864. CrossRef Medline

Oesch N, Euler T, Taylor WR (2005) Direction-selective dendritic action potentials in rabbit retina. Neuron 47:739-750. CrossRef Medline

Olveczky BP, Baccus SA, Meister M (2003) Segregation of object and background motion in the retina. Nature 423:401-408. CrossRef Medline

Oyster CW (1968) The analysis of image motion by the rabbit retina. J Physiol 199:613-635. CrossRef Medline

Pack CC, Hunter JN, Born RT (2005) Contrast dependence of suppressive influences in cortical area MT of alert macaque. J Neurophysiol 93:1809_ 1815. Medline

Preuss SJ, Trivedi CA, vom Berg-Maurer CM, Ryu S, Bollmann JH (2014) Classification of object size in retinotectal microcircuits. Curr Biol 24: 2376-2385. CrossRef Medline

Priebe NJ, Lisberger SG, Movshon JA (2006) Tuning for spatiotemporal frequency and speed in directionally selective neurons of macaque striate cortex. J Neurosci 26:2941-2950. CrossRef Medline

Purushothaman G, Marion R, Li K, Casagrande VA (2012) Gating and control of primary visual cortex by pulvinar. Nat Neurosci 15:905-912. CrossRef Medline

Roth MM, Dahmen JC, Muir DR, Imhof F, Martini FJ, Hofer SB (2016) Thalamic nuclei convey diverse contextual information to layer 1 of visual cortex. Nat Neurosci 19:299-307. CrossRef Medline

Sceniak MP, Ringach DL, Hawken MJ, Shapley R (1999) Contrast's effect on spatial summation by macaque V1 neurons. Nat Neurosci 2:733-739. CrossRef Medline

Sceniak MP, Hawken MJ, Shapley R (2002) Contrast-dependent changes in spatial frequency tuning of macaque V1 neurons: effects of a changing receptive field size. J Neurophysiol 88:1363-1373. Medline

Schwartz G, Taylor S, Fisher C, Harris R, Berry MJ 2nd (2007) Synchronized firing among retinal ganglion cells signals motion reversal. Neuron 55: 958-969. CrossRef Medline 
Sivyer B, Williams SR (2013) Direction selectivity is computed by active dendritic integration in retinal ganglion cells. Nat Neurosci 16:1848-1856. CrossRef Medline

Smith SL, Smith IT, Branco T, Häusser M (2013) Dendritic spikes enhance stimulus selectivity in cortical neurons in vivo. Nature 503:115-120. CrossRef Medline

Sun H, Frost BJ (1998) Computation of different optical variables of looming objects in pigeon nucleus rotundus neurons. Nat Neurosci 1:296-303. CrossRef Medline

Sun Q, Srinivas KV, Sotayo A, Siegelbaum SA (2014) Dendritic $\mathrm{Na}(+)$ spikes enable cortical input to drive action potential output from hippocampal CA2 pyramidal neurons. Elife 3. CrossRef Medline

Taniguchi H, He M, Wu P, Kim S, Paik R, Sugino K, Kvitsiani D, Kvitsani D, Fu Y, Lu J, Lin Y, Miyoshi G, Shima Y, Fishell G, Nelson SB, Huang ZJ (2011) A resource of Cre driver lines for genetic targeting of GABAergic neurons in cerebral cortex. Neuron 71:995-1013. CrossRef Medline

Trenholm S, McLaughlin AJ, Schwab DJ, Turner MH, Smith RG, Rieke F,
Awatramani GB (2014) Nonlinear dendritic integration of electrical and chemical synaptic inputs drives fine-scale correlations. Nat Neurosci 17: 1759-1766. CrossRef Medline

Zénon A, Krauzlis RJ (2012) Attention deficits without cortical neuronal deficits. Nature 489:434-437. CrossRef Medline

Zhang Y, Kim IJ, Sanes JR, Meister M (2012) The most numerous ganglion cell type of the mouse retina is a selective feature detector. Proc Natl Acad Sci U S A 109:E2391-8. CrossRef Medline

Zhao S, Ting JT, Atallah HE, Qiu L, Tan J, Gloss B, Augustine GJ, Deisseroth K, Luo M, Graybiel AM, Feng G (2011) Cell type-specific channelrhodopsin-2 transgenic mice for optogenetic dissection of neural circuitry function. Nat Methods 8:745-752. CrossRef Medline

Zhao X, Liu M, Cang J (2014) Visual cortex modulates the magnitude but not the selectivity of looming-evoked responses in the superior colliculus of awake mice. Neuron 84:202-213. CrossRef Medline

Zhou H, Schafer RJ, Desimone R (2016) Pulvinar-Cortex interactions in vision and attention. Neuron 89:209-220. CrossRef Medline 